ISSN: 2146-3042

DOI: $10.25095 /$ mufad.438654

\title{
Genişletilebilir İşletme Raporlama Dili'nin (XBRL) Finansal Raporlama Gelişimine Katkısı ve TMS Taksonomisi Uygulaması*
}

\author{
Aylin POROY ARSOY** \\ Yasemin ERTAN ${ }^{* * *}$ \\ Tuba BORA KILINÇARSLAN ${ }^{* * * *}$
}

\begin{abstract}
$\ddot{O Z Z E T}$
Finansal raporları Word, PDF, Excel, HTML gibi farklı elektronik formatlarla kaylt altına alınması finansal tablo kullanıcılarının işini zorlaştırmaktadır. Bu sebeple finansal raporlamada standart bir dilin gelişstirilmesi amacıyla Genişletilebilir Işsletme Raporlama Dili (XBRL) oluşturulmuştur. XBRL ile taksonomiler oluşturularak finansal veriler etiketlenmekte ve böylelikle finansal verilerin karşılaștırılması, tekrar kullanımı, paylașımı ve analizi kolaylaşmaktadır. Birçok ülkede finansal raporlama taksonomilerinin olușturulması ve geliştirilmesi için adımlar atılmıştır. Ülkemizde de Кати Gözetimi Muhasebe ve Denetim Standartları Kurumu tarafindan yapılan düzenleme ile birlikte Borsa İstanbul'da işlem gören işletmeler, 2016 yılının üçüncü çeyreğinden itibaren finansal tablolarını TMS Taksonomisi’ne uygun olarak Kaтиyu Aydınlatma Platformu'na yüklemeye basslamışlardır. Bu çallşmanın amacı, Türkiye'de muhasebe standartlarına göre raporlama yapan işletmelerin 2016 TMS Taksonomisi hakkindaki görüşlerini tespit etmektir. Bu amaçla yirmi dört sorudan olușan bir anket formu olușturulmuss ve bu form Borsa Istanbul'da ișlem gören 526 ișletmenin muhasebe departmaninda çalışanlarına e-mail yoluyla ulaştırlmıştır. Anketin güvenilirliği Cronbach a katsayısı ile test edilmiş, güvenilirlik katsayısı 0,922 olarak saptanmıştır. Araştırmaya katılanların çoğunluğu XBRL uygulamasının gerekli olduğunu ifade ederken, yaklaşık yarısı 2016 TMS Taksonomilerinin veri girişi için yeterliliği konusunda kararsızdır.
\end{abstract}

Anahtar Kelimeler: XBRL, UFRS, TMS Taksonomisi, KGK, Borsa İstanbul.

JEL Sinıflandirmasi: M41, M15.

Contribution to Financial Reporting Development of Extensible Business Reporting Language (XBRL) and TAS Taxonomy Practice

\section{ABSTRACT}

The recording of financial reports in different electronic formats such as Word, PDF, Excel and HTML makes the financial statement users job harder. For this reason, the Extensible Business Reporting Language (XBRL) was formed to develop a standard language in financial reporting. Taxonomies are created by using XBRL and financial data are labeled, thus facilitating the comparison, reuse, sharing and analysis of financial data. In many countries steps have been taken to form and develop financial reporting taxonomies. Companies that are traded in the Borsa Istanbul with the regulation formed by the Public Oversight Accounting and Auditing Standards Institution in our country have started to upload their financial statements to the Public Disclosure Platform in accordance with TAS Taxonomy from the third quarter of 2016. The aim of this study is to determine the opinions of the companies reporting in accordance with accounting standards in Turkey on the 2016 TAS Taxonomy. For this purpose, a questionnaire which consisting of twenty-four questions was created and this form was sent to the employees of the accounting department of 526 companies traded in Borsa Istanbul by e-mail. The reliability of the questionnaire was tested with the Cronbach $\alpha$ coefficient and the reliability coefficient was found to be 0.922 . While the majority of research participants state that XBRL implementation is necessary, approximately half of those are undecided about the adequacy of 2016 TAS Taxonomy for data entry.

Keywords: XBRL, IFRS, TAS Taxonomy, POA, Borsa Istanbul.

Jel Classification: M41, M15.

\footnotetext{
${ }^{*}$ Bu çalışma, KUAP(I)-2014/24 no.lu proje kapsamında Uludağ Üniversitesi Bilimsel Araştırma Projeleri tarafından desteklenmiştir.

** Prof. Dr. Aylin Poroy Arsoy, Uludağ Üniversitesi, İktisadi ve İdari Bilimler Fakültesi, aporoy@uludag.edu.tr

*** Dr. Öğr. Üyesi Yasemin Ertan, Uludağ Üniversitesi, İktisadi ve İdari Bilimler Fakültesi, yasertan@uludag.edu.tr

**** Arş. Gör. Tuba Bora Kılınçarslan, Uludağ Üniversitesi, İktisadi ve İdari Bilimler Fakültesi, tubabora@uludag.edu.tr
} 


\section{GİRiş}

Finansal raporlama entegre sermaye piyasalarının genişleme sürecine paralel olarak sürekli bir yenilenme içinde bulunmaktadır. UMSK tarafından yayınlanan ve dünyadaki pek çok ülkede kabul gören UMS/UFRS'lerin finansal raporlamanın globalleşmesi yönündeki katkısı tartışılmaz boyuttadır. Diğer yandan çağımızın bilgi anlamında en büyük paylaşım aracı olan internet yeni teknolojik bazlı finansal raporlama yöntemlerine çığır açmaktadır. $\mathrm{Bu}$ aşamada, XBRL hem global finansal raporlamayı hem de teknolojiyi içeren bir çözüm olarak karşımıza çıkmaktadır(Valentinetti ve Rea, 2012:164)

XBRL, şirketlerin işletme raporlamaları için tanımlanmış bilgisayar bazlı bir meta dildir. XBRL, finansal bilginin hazırlanması, yayınlanması ve takasını standardize eden bir yöntem sağlamayı amaçlayan XML'in (extensible markup language /genişletilebilir işaretleme dili) bir uygulamasıdır. Sistemde finansal veriler XBRL tarafindan "etiketlenmekte" ve bu "etiketleme" sistemi sayesinde işletme bilgilerinin paylaşımının artırılması sağlanmaktadır. XBRL'in mantıksal yapısı iki temel kavrama dayanmaktadır (Valentinetti ve Rea, 2013:238):

\footnotetext{
taksonomi

Verilerin etiketlenmesinde kullanılan unsurların hiyerarşisinden oluşan

XBRL'de etiketlenen işletme gerçeklerini içeren bir doküman olan örnek dökümanı.
}

Genel olarak taksonomi bir katalog veya bir sınıflandırma kuralları seti anlamına gelmektedir. Taksonomi, terimleri metadatalara (insanlar tarafindan okunabilecek kaynaklara) bağlar ve tipik bir taksonomi bir plan ve bağlantıları içerir.

XBRL taksonomileri XBRL dilinin kullanıldığı sözlüklerdir. Buradaki kategorizasyon planları, belirli veriler için (örneğin net kar) belirli etiketleri tanımlar (Ramin ve Reiman, 2013:377). Dolayısıyla XBRL taksonomisi, işletme raporlama terimlerinin bilgisayar ortamında okunabilir tanımlarını ve terimlerin aralarındaki ilişkileri içeren bir sözlüktür.

XBRL taksonomileri (sınıflandırmaları) iki temel gruba ayrılmaktadır:

1- $\quad$ XBRL-FR (Financial Reporting-Finansal Raporlama)

- Finansal raporlama süreçlerinde kullanılan finansal bilgilere ilişkin raporların standart hale getirilmesini sağlamak amacı ile kullanılmaktadır.

- $\quad$ Finansal raporlar diğer bir ifade ile sonuç bilgileri ile ilgilenmektedir.

- $\quad$ Standart formatları sayesinde, raporların otomatik işlenmesi, analiz edilmesi ve transferi mümkün hale gelmektedir.

2- $\quad$ XBRL-GL (Global Ledger-Büyük Defter) taksonomidir.

- Finansal bilgilerin muhasebe defterlerine kaydedilmesi için kullanılan

XML dilinde işaretleme dili olarak tanımlanan taksonomiler oluşturulduktan sonra, finansal olayları tanımlayan XBRL örnek dokümanları oluşturulmaktadır. Tanımlanan finansal olay tek bir bilanço kalemi olabileceği gibi finansal tablonun tamamı da olabilmektedir (Erkuş, 2008: 89). 


\section{XBRL'IN ORTAYA ÇIKIŞI VE GELIŞSIM SÜRECI}

Son dönemlerde bilişim teknolojilerinde ortaya çıkan gelişmeler, diğer işletme fonksiyonlarında olduğu gibi muhasebe fonksiyonunda ve özellikle finansal raporlama alanında köklü değişimlerin yaşanmasına neden olmuştur. 2000'li yıllarda ortaya çıkan finansal krizler, bilgi kullanıcılarının finansal raporlara olan güveninin sarsılmasına, bilgi kullanıcılarının daha şeffaf, ilgili ve zamanlı bilginin önemini kavramasına ve dolayısıyla bu doğrultudaki talebin artmasına neden olmuştur.

Finansal raporlamanın gelişimi incelendiğinde, önceleri kağıda dayalı olarak hazırlanan ve dağıtılan finansal verilerin, bilgi ihtiyacının artmasına paralel olarak PDF, Word, Excel, HTML gibi elektronik formatlarda hazırlanmaya başlandığı, bilgi kullanıcılarına da bu formatlarda iletildiği görülmektedir. Ancak PDF, Word, Excel gibi formatlarda hazırlanan finansal raporlardaki verilerin kullanılarak analiz edilebilmesi için verilerin tablolardan tek tek belirlenerek, ya tekrar yazılması ya da kopyalanması gerekmektedir. Bu durumda finansal analiz yapanlar açısından zaman alıcı olmakla birlikte verilerin toplanması aşamasında hata yapılması olasılığını arttırmaktadır. Bu sorunların ortadan kaldırılabilmesi için uluslararası alanda kullanılabilecek standart bir dil geliştirilmesi ihtiyacı ortaya çıkmıştır. XBRL fikri 1997 yılında Charlie Hoffman tarafından ortaya atılmış, 1999 yılında AICPA'nın katkılarıyla XBRL projesi hayata geçirilmiştir. Projenin başlangıç noktasını, Genişleyebilir Finansal Raporlama İşaretleme Dili (XFRML: Extensible Financial Reporting Markup Language) adlı bir çalışma oluşturmaktadır. 2000'de XML dili kullanılarak işletme hakkında elektronik ortamda hazırlanabilecek raporların sadece finansal raporlarla sınırlı kalamayacağ 1 düşüncesiyle, yeni dilin adı XFRML'den XBRL'ye dönüştürülmüş, çalışma grubunun adı da XBRL International olarak belirlenmiştir (Doğan 2013:130).

Ülkemizde de XBRL alanında yapılan çalışmalara destek vermek ve XBRL uygulamalarını ülkemize taşıyabilmek için 20 Kasım 2013 tarihinde XBRL Türkiye temsilciliği kurulmuştur. XBRL Yerel Temsilciliği ülkemizde XBRL ile ilgili çalışmalar yapmak üzere 4 farklı çalışma grubu oluşturmuştur. Bu çalışma gruplarından ilki taksonomi oluşturma, güncelleme ve finansal raporlama alanlarında çalışmalar yapmak üzere kurulmuştur. Denetim ve Vergi Denetim Dosyası isimli Çalışma Grubu 2'nin amacı ise vergi denetim süreçlerinde gerçekleştirilen bilgi akışlarına yönelik olmak üzere standart bir Vergi Denetim Dosyası (Tax Audit File) tanımına yönelik taksonominin XBRL-GL eklentisi veya bağımsız bir taksonomi şeklinde geliştirilmesi şeklinde belirlenmiştir. Çalışma Grubu 3 ve Çalışma Grubu 4 ise sırasıyla açık kaynak kodlu yazılım geliştirme ve eğitim, tanıtım ve araştırma faaliyetlerinde bulunmak üzere oluşturulmuştur.

\section{IASB VAKFI, UFRS TAKSONOMISİ VE XBRL}

International Accounting Standards Board (IASB) Vakfının amac1, dünyadaki entegre sermaye piyasalarında ortak bir finansal raporlama dili oluşturmaktır. XBRL ise işletme ve finansal raporlama için ortak elektronik bir format sağlamak için oluşturulmuştur (Ramin ve Reiman, 2013:377).

UFRS Taksonomisi, elektronik UFRS finansal tablolarının oluşturulması amacıyla IASB vakfi tarafindan yayınlanan global bir standarttır. UFRS taksonomisinin olușturulması ile muhasebe standartlarının elektronik ortamda doğru olarak kullanımı sağlanmış olmaktadır. 
UFRS taksonomisinin kapsamı, IASB tarafindan yayınlanan standartların sunum ve açıklama gerekliliklerini doğru olarak yansıtacak şekilde tasarlanmıştır. UFRS taksonomisinin kapsamı ayrıca, standartları eklerini oluşturan materyallerden (uygulama rehberi ve örnekler) elde edilen unsurları ve zorunlu olmayan ancak şirketler tarafindan çoğunlukla tercih edilen uygulamalara ilişkin açıklama unsurlarını da içermektedir.

UFRS Taksonomisi, UFRS açıklamalarının bir sınıflandırma sistemidir. IASB Vakfı, UFRS taksonomisi ile şirketlere UFRS'lerle uyumlu olarak hazırlanmış finansal tabloların elektronik versiyonları içerisinde "açıklamaların etiketlenmesi" imkanını veren bir işaret temelli standart sağlamaktadır. Tablo 1'de UFRS taksonomisinin kullanıcılara sağladığ 1 uygulama olanakları özetlenmektedir.

Tablo 1. UFRS Taksonomisinin Kullanıcılara Sağladığı Uygulama Olanakları

\begin{tabular}{|c|c|}
\hline KULLANICI & UYGULAMALAR \\
\hline Finansal Tablo Hazırlayıcılar & $\begin{array}{l}\text { Şirketler UFRS taksonomisini UFRS'lerle uyumlu finansal tablolarını } \\
\text { etiketlemek ve etiketlenmiş bu verileri kullanıcılarla elektronik olarak } \\
\text { paylaşmak amacıyla kullanmaktadırlar. Şirketler ayrıca dijital raporları } \\
\text { ve/veya UFRS taksonomisini sektörlerindeki diğer şirketlerin raporlama } \\
\text { uygulamalarını incelemek veya kıyaslama analizinin (benchmarking } \\
\text { analysis) yapılmasına yardımcı olmak amacıyla kullanabilmektedirler. }\end{array}$ \\
\hline Düzenleyici Kurumlar & $\begin{array}{l}\text { Düzenleyici kurumlar, elektronik dosyalama sistemlerini geliştirirken, } \\
\text { UFRS finansal tablolarını (veya bu tablolarda yer alan bilgileri) } \\
\text { etiketlemek amaciyla UFRS taksonomisini "'işaret kapsamlı standart", } \\
\text { olarak kullanabilmektedirler. Verilerin etiketlenmesi ile elde edilen, } \\
\text { yapılandırılmış bilgiler; UFRS'lerin tutarlı olarak adaptasyonu ve } \\
\text { geliştirilmesini desteklemek için sistematik analizlerin yapılması amacıyla } \\
\text { kullanabilmektedirler. Bu dosyalar aynı zamanda; sermaye piyasalarında } \\
\text { finansal bilgilerin şeffaflığını arttırmak amacıyla halka açı olarak da } \\
\text { sunulabilmektedir. }\end{array}$ \\
\hline $\begin{array}{l}\text { Yatırımcılar, Kredi verenler, } \\
\text { UFRS Finansal Tablolarının } \\
\text { Diğer Kullanıcıları }\end{array}$ & $\begin{array}{l}\text { Yatırımcılar ve kredi verenler işaretlenmiş elektronik UFRS finansal } \\
\text { tabloları; finansal verilere zamanında ve maliyet tasarruflu olarak ulaşmak } \\
\text { ve işlemek amacıyla kullanabilmektedirler. }\end{array}$ \\
\hline
\end{tabular}

Kaynak: IASB (2014), IFRS taxonomy guides: Guide to understanding the IFRS taxonomy update, August, p.5.

IASB Vakfinın XBRL için UFRS Taksonomisi oluşturmasının temel nedeni, sermaye piyasalarında elektronik raporlamaya doğru olan hareketi desteklemesidir. Zira UFRS ile uyumlu genel amaçlı finansal raporlama yapmanın en önemli nedenlerinden biri, sınır ötesi yatırımlara ulaşabilmektir. UFRS ile uyumlu finansal raporlar, dünyanın her yerinde bulunan 
yatırımcılar için erişilebilir olarak kurgulanmıştır. Halka açık şirketler için finansal raporların belirli bir formatta düzenlenmesi ve dosyalanması gerektiğinden, farklı ülkelerdeki sermaye piyasası düzenleyicileri ve menkul kıymet borsaları UFRS'ler ile uyumlu genel amaçlı raporlama erişimin öneminin bilincindedirler. Pek çok ülkede genel amaçlı finansal raporlamanın elektronik ortamda sunumunun geliştirilmesi için adımlar atılmıştır. Pek çok şirketin web sitesinde finansal raporların sadece pdf format1 ile yer alması yerine, istenen verilerin "etiketlenmesi" yöntemi ile finansal tablolardaki istenen verilere daha kolay ve daha az maliyetle erişim sağlanabilmektedir.

UFRS'ler ile uyumlu finansal tabloların elektronik raporlamasının yapılandırılması, IASB Vakfı'nın misyonuna üç açıdan katkı sağlamaktadır: (http://www.ifrs.org/xbrl/pages/xbrl.aspx)

- Şeffaflı̆̆ın desteklenmesi: Tüm piyasa taraflarının bilgiye erişimini artırır.

- Hesap verebilirliğin desteklenmesi: Yapılandırılmış elektronik veriler düzenleyiciler tarafından UFRS'lerin piyasa uygulamalarını destekler.

- $\quad$ Etkinliğin desteklenmesi: Verilere erişilebilirlik UFRS sürecinin maliyetini düşürebilmekte ve böylece kullanıcılar analize odaklanabilmektedir.

\section{IASB Vakfı'nın XBRL faaliyetleri şu şekildedir:}

- Taksonominin geliştirilmesi: UFRS'lere göre raporlama yapan şirketler için, her bir UFRS açıklaması (dipnotu) için etiketler yayınlamaktadır. Bu etiketler UFRS taksonomisi ile birlikte organize edilmektedir.

- Destekleyici materyaller: UFRS taksonomisinin kullanımını ve anlaşılmasını kolaylaştırmak için destekletici materyaller yayınlamaktadır.

- $\quad$ Tercümeler: Anahtar dillere UFRS taksonomisinin tercüme edilmesi, anadilleri İngilizce olmayan UFRS ve UFRS taksonomisi kullanıcılarının desteklenmesi için yapılmaktadır.

- Global yayılım: IASB Vakfi, UFRS ile bağlantılı XBRL'in kullanımını dünya çapında yaygınlaştırmak için ortak çabalar yürütmektedir. Vakıf ayrıca, UFRS taksonomisi kullanıcıları ile işbirliğini ve iletişimi teşvik etmektedir.

Nisan 2014'te kurulan UFRS Taksonomi Danışman Grubu (ITCG), IASB Vakfi'nın XBRL'den sorumlu iki komitesinin (XBRL Danışma Konseyi -XAC ve XBRL Kalite İnceleme Takımı - XQRT) yerini almıştır. ITCG'nin temel görevi, üyelerin UFRS taksonomisinin gelişimine katkıda bulunabilecekleri inceleme forumları düzenlemek ve teknik danışmanlık sağlamaktır.

ITCG, başkan ve başkan yardımcısı ile birlikte 16-20 kişilik üye sayısına sahiptir. Üyeler, farklı coğrafi alanlara ve fonksiyonel alt yapılara sahiptir. (http://www.iasplus.com/en/resources/ifrsf/advisory/itcg)

ITCG'nin üyeleri aşağıdaki işlevleri yerine getirirler: (http://www.ifrs.org/xbrl/pages/The-IFRS-Taxonomy-Consultative-Group-.aspx) 
- UFRS taksonomisinin derinlemesine incelenmesi ve taksonominin hem veri kapsamında hem de yapılandırma perspektifinde, beklenen piyasa standartlarını ve iyi uygulamaları karşılamasını sağlamak.

- $\quad$ UFRS taksonomisi ve UFRS dijital raporlama faaliyetlerine ilișkin konularda teknik danışmanlık ve stratejik uygulama rehberliği sağlamak. sağlama.

- $\quad$ Finansal raporlama ontolojisine ilişkin konularda UMSK personeline rehberlik

IASB Vakfı tarafından yürütülen taksonomi çalışmalarının başlangıcı 2002 yılına dayanmaktadır. Vakfin 2005 yılına kadar yayınladığı taksonomiler "nihai taslak" şeklinde kalmış, ancak 2005 yılında taksonomilerin son hali yayınlanmaya başlamıştır. Vakıf, 2005'ten sonra IAS/IFRS'lerin revizyonlarını göz önünde bulundurmak suretiyle taksonomileri revize edip, tekrar yayınlamaya devam etmiştir.

UFRS Taksonomisi, IASB Vakfi tarafından yeni bir standart yayınlanması veya bir standardın düzeltilmesi halinde yıl içinde güncellenmektedir. $\mathrm{Bu}$ güncellemeler aynı zamanda, ortak uygulama projelerinin veya teknolojik güncellemelerin bir sonucu olarak da yapılabilmektedir. Bir diğer deyişle taksonomi, her yıl "Yıllık UFRS Taksonomisi" adı altında yayınlanmaktadır. Bugüne kadar olan süreçte IASB Vakfi tarafından yayınlanan son şeklini almış taksonomiler Tablo 2'deki gibidir (http://www.ifrs.org/XBRL/IFRSTaxonomy/Pages/Previous-taxonomies.aspx):

Tablo 2. IFRS Taksonomileri

\begin{tabular}{|c|c|c|}
\hline IFRS Taksonomi Versiyonu & Yayınlanma Tarihi & Açıklama \\
\hline IFRS Taksonomisi 2006 & 15 Ağustos 2006 & $\begin{array}{l}31 \text { Aralık } 2005 \text { 'e kadar yayınlanan } \\
\text { IAS/IFRSler esas alınarak hazırlanmıştır. }\end{array}$ \\
\hline IFRS Taksonomisi 2008 & 1 Mart 2008 & $\begin{array}{l}31 \text { Aralık } 2007 \text { 'ye kadar yayınlanan } \\
\text { IAS/IFRSler esas alınarak hazırlanmıştır. }\end{array}$ \\
\hline IFRS Taksonomisi 2009 & 2 Nisan 2009 & $\begin{array}{l}31 \text { Aralık 2008'e kadar yayınlanan } \\
\text { IAS/IFRSler esas alınarak hazırlanmıştır. }\end{array}$ \\
\hline IFRS Taksonomisi 2010 & 30 Nisan 2010 & $\begin{array}{c}1 \text { Ocak 2010'a kadar yayınlanan IAS/IFRSler } \\
\text { esas alınarak hazırlanmıştır. }\end{array}$ \\
\hline IFRS Taksonomisi 2011 & 25 Mart 2011 & $\begin{array}{c}1 \text { Ocak 2011'e kadar yayınlanan IAS/IFRSler } \\
\text { esas alınarak hazırlanmıştır. }\end{array}$ \\
\hline IFRS Taksonomisi 2012 & 30 Mart 2012 & $\begin{array}{l}1 \text { Ocak 2012'ye kadar yayınlanan } \\
\text { IAS/IFRSler esas alınarak hazırlanmıştır. }\end{array}$ \\
\hline IFRS Taksonomisi 2013 & 27 Mart 2013 & $\begin{array}{c}1 \text { Ocak 2013'e kadar yayınlanan IAS/IFRSler } \\
\text { esas alınarak hazırlanmıştır }\end{array}$ \\
\hline
\end{tabular}




\begin{tabular}{||c||c|c||}
\hline IFRS Taksonomisi 2014 & 5 Mart 2014 & $\begin{array}{c}\text { Ocak 2014'e kadar yayınlanan IAS/IFRSler } \\
\text { esas alınarak hazırlanmıştır. }\end{array}$ \\
\hline \hline IFRS Taksonomisi 2015 & 11 Mart 2015 & $\begin{array}{r}\text { Ocak 2015'e kadar yayınlanan IAS/IFRSler } \\
\text { esas alınarak hazırlanmıştır. }\end{array}$ \\
\hline \hline IFRS Taksonomisi 2016 & 31 Mart 2016 & $\begin{array}{c}\text { 13 Ocak 2016'ya kadar yayınlanan } \\
\text { IAS/IFRSler esas alınarak hazırlanmıştır. }\end{array}$ \\
\hline \hline IFRS Taksonomisi 2017 & 9 Mart 2017 & $\begin{array}{c}\text { 1 Ocak 2017'ya kadar yayınlanan } \\
\text { IAS/IFRSler esas alınarak hazırlanmıştır. }\end{array}$ \\
\hline \hline
\end{tabular}

UFRS ile XBRL'in güçlü kombinasyonu muhasebe standartlarını ve kavramların anlayan kişilerin ve finansal bilgileri teknolojik araçları kullanarak bölümleyen ve organize eden kişilerin ihtiyaçlarını karşılamaktadır. XBRL, UFRS ile işletme raporlamasının daha iyi ve daha hızı yapılması konusunda mükemmel bir ortaklık oluşturmaktadır (Ramin ve Reiman, 2013:374). Finansal bilgilerin şeffaflığını, kalitesini ve karşılaştırılabilirliğini artırmak hem UFRS hem de XBRL'in ortak amacidır.

\section{ARAȘTIRMA METODOLOJISİ}

\subsection{Araştırmanın Amacı, Kapsamı ve Yöntemi}

Ülkemizde KGK tarafından XBRL ile ilgili çalışmalara 2013 yılında başlanmış, TMS'ye uygun finansal tabloların (dipnotlar hariç) XBRL formatında gerçekleştirilecek finansal raporlama ihtiyaçlarını karşılamak üzere oluşturulan 2016 TMS Taksonomisi 2 Haziran 2016 tarihinde KGK'nın internet sitesinde yayımlanmıştır (https://www.kgk.gov.tr/contents/files/TMSTaksonomosi/TaksonomiDuyuruMetni.pdf).

Türkiye'de halkla açık şirketler kamuyu aydınlatma platformuna (www.kap.gov.tr) finansal tablolarını yüklerken TMS Taksonomisi 2016 versiyonunu kullanmaktadırlar. Yapılan düzenleme ile halka açık şirketler 2016 yılının 3. çeyreğinden itibaren (9 aylık) finansal tablolarını taksonomiye uygun olarak siteye yüklemeye başlamışlardır.

$\mathrm{Bu}$ çalışmanın amacı, KGK tarafindan oluşturulan 2016 TMS Taksonomisi'nin ülkemizde muhasebe standartlarına göre raporlama yapan XBRL kullanıcıları açısından nasıl değerlendirildiğini incelemektir. Bu amaçla Yıldırım ve Sağlar (2014)'ın anket formundan yararlanılarak yirmi dört sorudan oluşan yeni bir anket formu oluşturulmuştur. Anket formu iki bölüm olarak tasarlanmıştır. İlk bölümde anketi cevaplayanların özelliklerine ilişkin sorulara, ikinci bölümde ise 2016 TMS Taksonomisi ile ilgili bilgi düzeylerini ve düşüncelerini ölçmeye yönelik 5'li likert ölçeği ile hazırlanmış sorulara yer verilmiştir. Anket formu finansal raporlama konusunda uzman 7 kişi tarafından (4 akademisyen ve 3 serbest muhasebeci mali müşavir olmak üzere) incelenmiş, uzmanların önerileri doğrultusunda düzenlenerek içerik geçerliliği sağlanmıştır. Araştırma için hazırlanan anket formunun güvenilirliği öncelikle BIST’te işlem gören 30 işletme üzerinde uygulanarak test edilmiştir. SPSS 22 paket programı kullanılarak yapılan güvenilirlik testinde Cronbach $\alpha$ güvenilirlik katsayısı 0,922 olarak saptanmıştır. Daha sonra anket formu, Eylül 2016'da TMS 
Taksonomisi'ni ilk defa kullanmaya başlamış olan halka açık 526 işletmenin muhasebe departmanında çalışanlarına e-mail yoluyla gönderilmiş ve 178 işletmeden veri elde edilebilmiştir. Dolayısıyla anketin geri dönüș oranı \% 33.84’tür.

\subsection{Araştırma Sonucunda Elde Edilen Bulgular}

Verilerin elde edilmesinde kullanılan anket formunun ilk bölümünde araştırmaya katılan kişilerin demografik bilgilerine ilişkin sorulara yer verilmiştir. Demografik bilgilere ilişkin veriler Tablo 3'de yer almaktadır.

Tablo 3. Demografik Bilgiler

\begin{tabular}{|c|c|c|}
\hline Cinsiyet & Kişi Sayısı & Toplam Cevaplayanlar İ̧̧indeki Yüzdesi \\
\hline Kadın & 50 & 28,1 \\
\hline Erkek & 128 & 71,9 \\
\hline Toplam & 178 & 100,0 \\
\hline Yaş Aralığı & Kişi Sayısı & Toplam Cevaplayanlar İçindeki Yüzdesi \\
\hline $22-30$ & 31 & 17,4 \\
\hline $31-40$ & 72 & 40,4 \\
\hline $41-50$ & 55 & 30,9 \\
\hline $51-60$ & 16 & 9,0 \\
\hline $61-70$ & 4 & 2,2 \\
\hline Toplam & 178 & 100,0 \\
\hline Ĕ̆itim Düzeyi & Kişi Sayısı & Toplam Cevaplayanlar İçindeki Yüzdesi \\
\hline Lisans & 123 & 69,1 \\
\hline Yüksek Lisans & 55 & 30,9 \\
\hline Toplam & 178 & 100,0 \\
\hline İşletmedeki Pozisyon & Kişi Sayısı & Toplam Cevaplayanlar İçindeki Yüzdesi \\
\hline Sorumlu/Yetkili & 24 & 13,5 \\
\hline Uzman Yardımcisı & 8 & 4,5 \\
\hline Uzman & 27 & 15,2 \\
\hline Yönetici & 52 & 29,2 \\
\hline Müdür Yardımcısı & 12 & 6,7 \\
\hline Şef/Müdür & 55 & 30,9 \\
\hline Toplam & 178 & 100,0 \\
\hline
\end{tabular}




\begin{tabular}{|c|c||c||}
\hline Mesleki Deneyim & Kişi Sayısı & Toplam Cevaplayanlar Içindeki Yüzdesi \\
\hline \hline $1-5$ yll & 70 & 39,3 \\
\hline \hline $6-10$ yll & 36 & 20,2 \\
\hline $11-15$ yll & 28 & 15,7 \\
\hline $16-20$ yll & 28 & 15,7 \\
\hline $21-25$ yll & 12 & 6,7 \\
\hline \hline 26 ve üstü yll & 4 & 2,2 \\
\hline \hline Toplam & $\mathbf{1 7 8}$ & $\mathbf{1 0 0 , 0}$ \\
\hline
\end{tabular}

Tablo III'den de görüldüğü üzere, araştırmaya katılanların çoğunluğunu $(\% 71,9)$ erkek çalışanlar oluşturmaktadır. En çok 31-40 yaş aralığındaki çalışanlar $(\% 40,4)$ araştırmaya katılırken, bunu \%30,9 ile 41-50 yaş aralığındaki çalışanlar izlemektedir. 61-70 yaş aralığındaki çalışanlar $(\% 2,2)$ ise araştırmaya en az katılan gruptur. Araştırmaya katılanların çoğunluğu $(\% 69,1)$ lisans mezunlarından, \% 30,9'u ise yüksek lisans mezunlarından oluşturmaktadır. Araştırmaya katılanlar arasında doktora mezunu bulunmamaktadır. Araştırmaya katılanların çalıştıkları işletmedeki pozisyonlarına bakıldığında, en çok katılım gösterenlerin işletmede şef/müdür (muhasebe şefi, mali işler müdürü, muhasebe ve finansal raporlama müdürü, bütçe ve raporlama müdürü, denetim müdürü vb.) $(\% 30,9)$ ve yönetici (finans yöneticisi, mali kontrol ve raporlama yöneticisi, mali işler yöneticisi, yatırımcı ilişkileri yöneticisi, muhasebe ve vergi yöneticisi vb.) $(\% 29,2)$ pozisyonunda çalıştığ 1 görülmektedir. Dolayısıyla araştırmaya katılanların çoğunluğunun üst pozisyonlarda yer aldığ1 söylenilebilir. Araştırmaya en çok katılım sağlayanlar $(39,3)$ 1-5 yıl arasında mesleki deneyime sahip olurken, en az katılım gösterenler ise $(\% 2,2)$ en deneyimli çalışanlardan oluşmaktadır. Mesleki deneyim süresi arttıkça araştırmaya katılan kişi sayısının azaldığ görülmektedir.

Anket formunun ikinci bölümü, BIST'te işlem gören işletmelerdeki muhasebe departmanı çalışanlarının 2016 TMS Taksonomisi ile ilgili bilgi seviyelerini ve düşüncelerini ölçmek üzere tasarlanmıştır. Anketin ikinci bölümünde yer alan ifadeler ve araştırmaya katılanların bu ifadelerle ilgili görüşleri Tablo 4'de görüldüğü gibidir.

Tablo 4. TMS XBRL Taksonomisi ile İlgili Sahip Olunan Bilgi ve Düşünceler

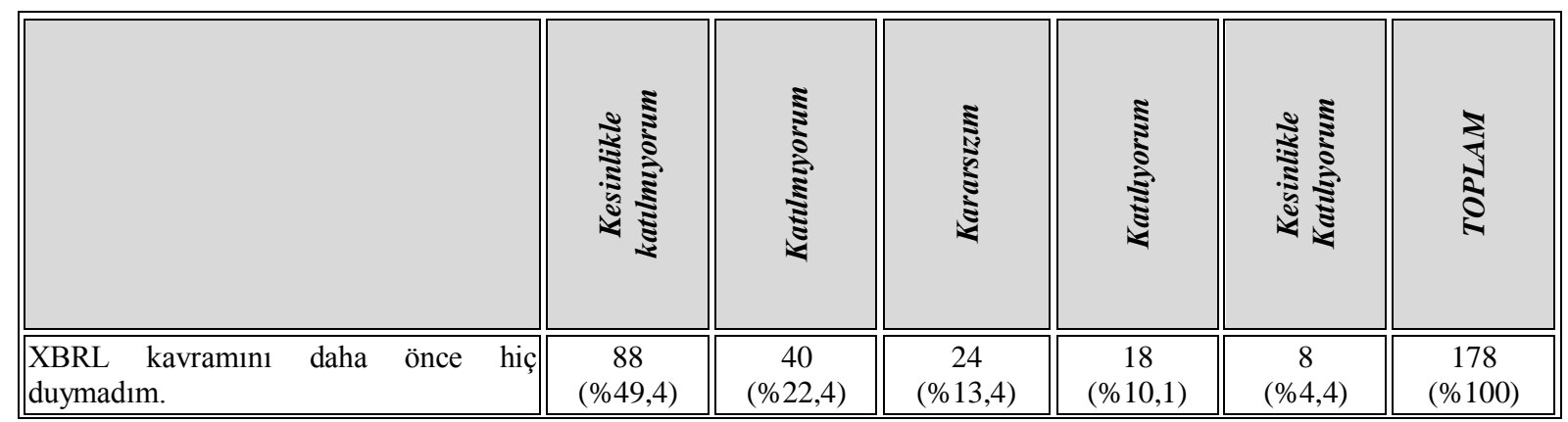




\begin{tabular}{|c|c|c|c|c|c|c|}
\hline $\begin{array}{l}\text { XBRL'i kavram olarak duydum, ancak } \\
\text { ne işe yaradığ } 1 \text { konusunda herhangi bir } \\
\text { bilgiye sahip değilim. }\end{array}$ & $\begin{array}{c}67 \\
(\% 36,7)\end{array}$ & $\begin{array}{c}52 \\
(\% 29,2)\end{array}$ & $\begin{array}{c}28 \\
(\% 15,7)\end{array}$ & $\begin{array}{c}12 \\
(\% 6,7)\end{array}$ & $\begin{array}{c}16 \\
(\% 9,0)\end{array}$ & $\begin{array}{c}175 \\
(\% 98,3)\end{array}$ \\
\hline $\begin{array}{l}\text { XBRL uygulamasi hakkında yeterli } \\
\text { düzeyde bilgi sahibiyim. }\end{array}$ & $\begin{array}{c}70 \\
(\% 39,3) \\
\end{array}$ & $\begin{array}{c}32 \\
(\% 18,0) \\
\end{array}$ & $\begin{array}{c}28 \\
(\% 15,7) \\
\end{array}$ & $\begin{array}{c}24 \\
(\% 13,5) \\
\end{array}$ & $\begin{array}{c}20 \\
(\% 11,2) \\
\end{array}$ & $\begin{array}{c}174 \\
(\% 97,8) \\
\end{array}$ \\
\hline $\begin{array}{ll}\text { XBRL uygulamasını } & \text { gerekli } \\
\text { görmüyorum. }\end{array}$ & $\begin{array}{c}76 \\
(\% 42,7)\end{array}$ & $\begin{array}{c}44 \\
(\% 24,7)\end{array}$ & $\begin{array}{c}31 \\
(\% 17,4)\end{array}$ & $\begin{array}{c}4 \\
(\% 2,2)\end{array}$ & $\begin{array}{c}12 \\
(\% 6,7)\end{array}$ & $\begin{array}{c}167 \\
(\% 93,8)\end{array}$ \\
\hline $\begin{array}{l}\text { XBRL uygulaması finansal bilgi } \\
\text { kullanıcılarına finansal şeffaflığın } \\
\text { sağlanması yönünde etkilidir. }\end{array}$ & $\begin{array}{c}16 \\
(\% 9,0)\end{array}$ & $\begin{array}{c}4 \\
(\% 2,2)\end{array}$ & $\begin{array}{c}36 \\
(\% 20,2)\end{array}$ & $\begin{array}{c}52 \\
(\% 29,2)\end{array}$ & $\begin{array}{c}52 \\
(\% 29,2)\end{array}$ & $\begin{array}{c}160 \\
(\% 89,9)\end{array}$ \\
\hline $\begin{array}{l}\text { XBRL uygulaması } \quad \text { UMS/UFRS'lerin } \\
\text { sağladığı bilgileri standardize etmektedir. }\end{array}$ & $\begin{array}{c}12 \\
(\% 6,7)\end{array}$ & $\begin{array}{c}8 \\
(\% 4,5)\end{array}$ & $\begin{array}{c}36 \\
(\% 20,2)\end{array}$ & $\begin{array}{c}56 \\
(\% 31,5)\end{array}$ & $\begin{array}{c}56 \\
(\% 31,5)\end{array}$ & $\begin{array}{c}168 \\
(\% 94,4)\end{array}$ \\
\hline $\begin{array}{l}\text { XBRL kullanımı ile finansal bilgilerin } \\
\text { iletilmesi daha hızlı olacaktır. }\end{array}$ & $\begin{array}{c}12 \\
(\% 6,7)\end{array}$ & $\begin{array}{c}4 \\
(\% 2,2) \\
\end{array}$ & $\begin{array}{c}32 \\
(\% 18,0) \\
\end{array}$ & $\begin{array}{c}52 \\
(\% 29,2) \\
\end{array}$ & $\begin{array}{c}64 \\
(\% 36,0) \\
\end{array}$ & $\begin{array}{c}164 \\
(\% 92,1) \\
\end{array}$ \\
\hline XBRL uygulaması uzmanlık gerektirir. & $\begin{array}{c}12 \\
(\% 6,7)\end{array}$ & $\begin{array}{c}8 \\
(\% 4,5)\end{array}$ & $\begin{array}{c}44 \\
(\% 24,7)\end{array}$ & $\begin{array}{c}48 \\
(\% 27,0)\end{array}$ & $\begin{array}{c}48 \\
(\% 27,0)\end{array}$ & $\begin{array}{c}160 \\
(\% 89,9)\end{array}$ \\
\hline 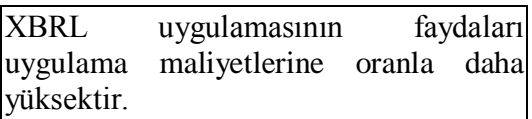 & $\begin{array}{c}12 \\
(\% 6,7)\end{array}$ & $\begin{array}{c}16 \\
(\% 9,0)\end{array}$ & $\begin{array}{c}16 \\
(\% 9,0)\end{array}$ & $\begin{array}{c}44 \\
(\% 24,7)\end{array}$ & $\begin{array}{c}76 \\
(\% 42,7)\end{array}$ & $\begin{array}{c}164 \\
(\% 92,1)\end{array}$ \\
\hline $\begin{array}{l}\text { XBRL uygulaması ile bağımsız denetim } \\
\text { daha hatasız gerçekleştirilebilir. }\end{array}$ & $\begin{array}{c}12 \\
(\% 6,7) \\
\end{array}$ & $\begin{array}{c}16 \\
(\% 9,0) \\
\end{array}$ & $\begin{array}{c}60 \\
(\% 33,7) \\
\end{array}$ & $\begin{array}{c}48 \\
(\% 27,0) \\
\end{array}$ & $\begin{array}{c}28 \\
(\% 15,7) \\
\end{array}$ & $\begin{array}{c}164 \\
(\% 92,1) \\
\end{array}$ \\
\hline $\begin{array}{l}\text { XBRL uygulaması finansal bilgi akışını } \\
\text { basit ve kolay anlaşılır bir yapıya } \\
\text { dönüştürmektedir. }\end{array}$ & $\begin{array}{c}12 \\
(\% 6,7)\end{array}$ & $\begin{array}{c}4 \\
(\% 2,2)\end{array}$ & $\begin{array}{c}36 \\
(\% 20,2)\end{array}$ & $\begin{array}{c}72 \\
(\% 40,4)\end{array}$ & $\begin{array}{c}36 \\
(\% 20,2)\end{array}$ & $\begin{array}{c}160 \\
(\% 89,9)\end{array}$ \\
\hline 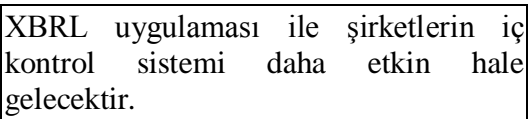 & $\begin{array}{c}16 \\
(\% 9,0)\end{array}$ & $\begin{array}{c}8 \\
(\% 4,5)\end{array}$ & $\begin{array}{c}40 \\
(\% 22,5)\end{array}$ & $\begin{array}{c}68 \\
(\% 38,2)\end{array}$ & $\begin{array}{c}28 \\
(\% 15,7)\end{array}$ & $\begin{array}{c}160 \\
(\% 89,9)\end{array}$ \\
\hline $\begin{array}{l}\text { XBRL uygulaması ile finansal verilerin } \\
\text { analizi ve karşışaştırılması daha güvenilir } \\
\text { olacaktır. }\end{array}$ & $\begin{array}{c}12 \\
(\% 6,7)\end{array}$ & $\begin{array}{c}4 \\
(\% 2,2)\end{array}$ & $\begin{array}{c}28 \\
(\% 15,7)\end{array}$ & $\begin{array}{c}84 \\
(\% 47,2)\end{array}$ & $\begin{array}{c}32 \\
(\% 18,0)\end{array}$ & $\begin{array}{c}160 \\
(\% 89,9)\end{array}$ \\
\hline $\begin{array}{l}\text { XBRL uygulamas1 finansal bilgilerin } \\
\text { kalitesini artıracaktır. }\end{array}$ & $\begin{array}{c}8 \\
(\% 4,5) \\
\end{array}$ & $\begin{array}{c}4 \\
(\% 2,2) \\
\end{array}$ & $\begin{array}{c}32 \\
(\% 18,0)\end{array}$ & $\begin{array}{c}80 \\
(\% 44,9)\end{array}$ & $\begin{array}{c}40 \\
(\% 22,5)\end{array}$ & $\begin{array}{c}164 \\
(\% 92,1) \\
\end{array}$ \\
\hline $\begin{array}{l}\text { XBRL uygulaması ile veriler otomatik } \\
\text { olarak üretileceğinden, bu uygulama } \\
\text { maliyet tasarrufu sağlayacaktır. }\end{array}$ & $\begin{array}{c}12 \\
(\% 6,7)\end{array}$ & $\begin{array}{c}4 \\
(\% 2,2)\end{array}$ & $36(\% 20,2)$ & $68(\% 38,2)$ & $44(\% 24,7)$ & $\begin{array}{c}164 \\
(\% 92,1)\end{array}$ \\
\hline $\begin{array}{l}\text { TMS } 2016 \text { taksonomisi finansal durum } \\
\text { tablosu XBRL veri girişi için yeterlidir. }\end{array}$ & $\begin{array}{c}8 \\
(\% 4,5) \\
\end{array}$ & $\begin{array}{c}4 \\
(\% 2,2) \\
\end{array}$ & $\begin{array}{c}88 \\
(\% 49,4) \\
\end{array}$ & $\begin{array}{c}36 \\
(\% 20,2) \\
\end{array}$ & $\begin{array}{c}16 \\
(\% 9,0) \\
\end{array}$ & $\begin{array}{c}152 \\
(\% 85,4) \\
\end{array}$ \\
\hline $\begin{array}{l}\text { TMS } 2016 \text { taksonomisi kar veya zarar } \\
\text { tablosu XBRL veri girişi için yeterlidir. }\end{array}$ & $\begin{array}{c}12 \\
(\% 6,7)\end{array}$ & $\begin{array}{c}4 \\
(\% 2,2)\end{array}$ & $\begin{array}{c}88 \\
(\% 49,4) \\
\end{array}$ & $\begin{array}{c}44 \\
(\% 24,7)\end{array}$ & $\begin{array}{c}4 \\
(\% 2,2)\end{array}$ & $\begin{array}{c}152 \\
(\% 85,4) \\
\end{array}$ \\
\hline \begin{tabular}{|l} 
TMS 2016 taksonomisi nakit ak1ş \\
tablosu XBRL veri girişi için yeterlidir.
\end{tabular} & $\begin{array}{c}12 \\
(\% 6,7)\end{array}$ & $\begin{array}{c}4 \\
(\% 2,2)\end{array}$ & $\begin{array}{c}96 \\
(\% 53,9)\end{array}$ & $40(\% 22,5)$ & $\begin{array}{c}12 \\
(\% 6,7)\end{array}$ & $\begin{array}{c}164 \\
(\% 92,1)\end{array}$ \\
\hline 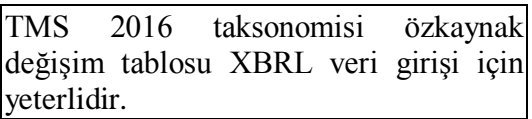 & $\begin{array}{c}12 \\
(\% 6,7)\end{array}$ & $\begin{array}{c}8 \\
(\% 4,5)\end{array}$ & $\begin{array}{c}92 \\
(\% 51,7)\end{array}$ & $40(\% 22,5)$ & $\begin{array}{c}12 \\
(\% 6,7)\end{array}$ & $\begin{array}{c}164 \\
(\% 92,1)\end{array}$ \\
\hline
\end{tabular}

Tablo IV'den de görüldüğü üzere araştırmaya katılanların \%14,5'i XBRL kavramını daha önce duymadığını ifade ederken, \% 15,7'si XBRL'i kavram olarak duyduğunu, ancak ne işe yaradığı konusunda herhangi bir bilgiye sahip olmadığını, diğer \%24,7'si XBRL uygulaması hakkında yeterli düzeyde bilgi sahibi olduklarını ifade etmişlerdir. XBRL uygulaması halka açık işletmeler için 2016 yılının 3. çeyreğinden itibaren zorunlu olmasına rağmen, araştırmaya katılanların \%29,2'sinin XBRL kavramını duymaması ya da bu konuda 
herhangi bir bilgiye sahip olmaması, araştırmaya katılanların raporlama aşamasında yer almadığının göstergesi olarak yorumlanabilir.

Araştırmaya katılanların çoğunluğu $(\% 67,4)$ XBRL uygulamalarını gerekli görmektedir. Çünkü araştırmaya katılanların \%58,4’ü XBRL uygulamasıyla birlikte finansal şeffaflığın artacağını, \%63'ü UMS/UFRS'lerle sağlanan bilgilerin standardize edileceğini, $\% 65,2$ 'si finansal bilgilerin iletilmesinin daha hızlı olacağını, \%42,7'si ile bağımsız denetim daha hatasız gerçekleştirileceğini, \%60,6'sı finansal bilgi akışının basit ve kolay anlaşılır bir yapıya dönüşeceğini, \%53,9'u şirketlerin iç kontrol sisteminin daha etkin hale geleceğini, \%65,2'si finansal verilerin analizinin ve karşılaştırılmasının daha güvenilir olacağııı, \%67,4’ü finansal bilgilerin kalitesinin artacağını düşünmektedirler. Bununla birlikte araştırmaya katılanların \%62,9'u XBRL uygulaması ile veriler otomatik olarak üretileceğinden, bu uygulamanın maliyet tasarrufu sağlanacağ 1 ve \%67'4'ü faydasının maliyetinden daha çok olacağı görüşündedir. Araştırmaya katılanların \%54'ü de XBRL uygulamasının uzmanlık gerektirdiği kanaatindedir.

Araştırmaya katılanların yaklaşık yarısı TMS 2016 taksonomisi finansal durum tablosu, kar veya zarar tablosu, nakit akış tablosu ve özkaynak değişim tablosunun XBRL veri girişi için yeterliliği konusunda kararsızdır.

\section{SONUÇ}

Farklı ulusal düzenlemelere göre yapılandırılmış pek çok farklı XBRL taksonomileri, XBRL'in global yayılım stratejisi önünde bir engel teşkil etmektedir. Eğer XBRL taksonomilerinin temelleri farklı olursa, kullanıcılar farklı ülkelerde bulunan şirketlerin finansal bilgilerini karşılaştırma olanağını bulamayacaklardır (Bonson vd. 2009:57). Bu sorunun çözümü IASB Vakfı'nın geliştirdiği UFRS Taksonomileri ile çözümlenebilmektedir.

Dünyada farklı ülkelerde pek çok düzenleyici kurum, finansal bilgilerin iletilmesini basitleştiren ve geliştiren XBRL uygulamalarının adaptasyonu için çaba göstermektedir. XBRL uygulamaları günümüzde, dünya çapında 50'den fazla ülkede uygulanmaktadır. Böylece kağıt temelli raporlamaya göre çok daha fazla kullanışlı, etkin ve doğru raporların hazırlanması mümkün olmuştur.

Ülkemizde de 2013 yılında KGK tarafindan XBRL ile ilgili çalışmalara başlanmış, 2 Haziran 2016 tarihinde 2016 TMS Taksonomisi oluşturularak halka açık şirketlerin dokuz aylık finansal tablolarından itibaren taksonomiye uygun olarak hazırlanması ve kamuyu aydınlatma platformuna bu şekilde yüklenmesi zorunluluğu getirilmiştir.

Yıldırım ve Sağlar (2014) tarafından yapılan çalışmada, ülkemizde araştırmaya katılan halka açı şirketlerin \%53,6'sı XBRL hakkında bilgi sahibi olmazken, TMS Taksonomilerinin halka açık şirketler için zorunlu hale getirilmesiyle birlikte bu çalışmada bu oranın düştüğü ve XBRL uygulamaları konusunda halka açık şirketlerin muhasebe departmanında çalışanlarının farkındalık seviyelerinin arttığı söylenebilir. Ancak halka açık şirketlerde bu seviye daha da artırılmalı, zorunlu olan TMS Taksonomisi uygulaması konusunda muhasebe departmanında çalışan tüm personelin bilgilendirilmesi sağlanmalıdır. 
Finansal bilginin ulusal sınırları aşıp, sınır ötesine ulaştı̆̆ı bu günlerde, finansal raporlamanın tek bir formatta yapılması finansal bilgi kullanıcıları açısından oldukça önem arz etmektedir. Araştırmaya katılan halka açı şirketlerde muhasebe departmanında çalışanların çoğunluğunun XBRL uygulamalarını gerekli görmesi ve yararlarının farkında olması, ülkemiz açısından olumlu bir gelişme olarak değerlendirilebilir.

\section{KAYNAKLAR}

Bonson, Enrique - Cortijo, Virginia - Escobar, Tomas (2009), "Towards the global adoption of XBRL using International Financial Reporting Standards (IFRS)”, International Journal of Accounting Information Systems, 10(1), pp. 46-60.

Doğan, Mustafa (2013), “Genişletilebilir işletme raporlama dili (XBRL): eleştirel bir bakış”, Muhasebe Bilim Dünyası Dergisi, 15(2), ss. 145-161.

Erkuş, Hakan (2008), XBRL Genişletilebilir işletme raporlama dili, Gazi Kitabevi, Ankara.

IASB (2014), IFRS taxonomy guides: Guide to understanding the IFRS taxonomy update. $\quad$ http://www.ifrs.org/-/media/feature/standards/taxonomy/generalresources/understanding-ifrs-taxonomy-update.pdf

Ramin, Kurt - Reiman, Cornelis (2013), IFRS and XBRL: How to improve business reporting through Technology and objective tracking, Wiley Publication.

Valentinetti, Diego - Rea, Michele A. (2012), "IFRS Taxonomy and financial reporting practices: The case of Italian listed companies", International Journal of Accounting Information Systems, 13(2), pp. 163-180.

Valentinetti Diego - Rea, Michele A. (2013), "XBRL for financial reporting: Evidence on Italian GAAP versus IFRS”, Accounting Perspectives, 12(3), pp. 237-259.

Yıldırım, Meriç - Sağlar, Jale (2014), "Finansal tabloların sunumunda XBRL kullanımı: ABD örneği ve Türkiye'de uygulanabilirliği”, Anadolu Üniversitesi Sosyal Bilimler Dergisi, 14(4), ss. 69-82.

www.iasplus.com/en/resources/ifrsf/advisory/itcg

www.ifrs.org/XBRL/IFRS-Taxonomy/Pages/Previous-taxonomies.aspx

www.ifrs.org/xbrl/pages/The-IFRS-Taxonomy-Consultative-Group-.aspx

www.ifrs.org/xbrl/pages/xbrl.aspx

www.kap.gov.tr

www.kgk.gov.tr/contents/files/TMSTaksonomosi/TaksonomiDuyuruMetni.pdf 